Research Article

\title{
Screening of bone mineral density by densitometer and correlation with serum calcium and vitamin D levels to detect early osteoporotic changes in postmenopausal women in slum areas of Raipur and Kalupur of Ahmedabad
}

\author{
Adarshjit Singh $^{1 *}$, Harpreet Singh ${ }^{2}$, Safal Patel ${ }^{3}$
}

\begin{abstract}
${ }^{1}$ Department of Pharmacology, AMC MET Medical College, Ahmedabad, Gujarat, India, ${ }^{2}$ Department of Radiology, ${ }^{3}$ Intern, Surat Municipal Institute of Medical Education and Research, Gujarat, India
\end{abstract}

Received: 15 September 2015 Accepted: 18 September 2015

\section{*Correspondence to:}

Adarshjit Singh,

Email: adarshjit@yahoo.com

Copyright: (C) the author(s), publisher and licensee Medip Academy. This is an openaccess article distributed under the terms of the Creative Commons Attribution NonCommercial License, which permits unrestricted noncommercial use, distribution, and reproduction in any medium, provided the original work is properly cited.

\begin{abstract}
Background: Osteoporosis is a rising health difficulty, which is renowned in both developed and developing countries. It is linked with considerable morbidity and socio-economic burden worldwide. Various factors are responsible for osteoporosis such as race, family history, body weight, estrogen deficiency (menopause), low calcium intake, and many others. The present study was aimed to early prediction and evaluates the prevalence of osteoporosis in postmenopausal women of slum area of Ahmedabad (Raipur and Kalupur).

Methods: The prospective, single-center study included 230 postmenopausal women. Baseline demographic characteristics were recorded using standard pre-designed case record form. Eligible patients according to inclusion and exclusion criteria were underwent for dual-energy X-ray absorptiometry (DEXA) scan to measure bone mass density at the lumbar spine, femoral neck, and hip bone. Laboratory investigations such as serum calcium and serum vitamin D were performed according to standard procedure. Prediction for early detection of osteopenia and osteoporosis was evaluated based on T-score (DEXA scan).

Results: The overall prevalence of osteopenia and osteoporosis were found $28.69 \%$ and $44.34 \%$, respectively. Prevalence of osteoporosis was found higher $(50.72 \%)$ in study population belongs to age between 51 and 60 years, whereas the prevalence of osteopenia was higher (38.53\%) in age group (41-50). In further, normal body mass index was associated with the higher prevalence of osteopenia and osteoporosis. The calcium deficiency, vitamin D deficiency, family history of osteoporosis were found major risk factor associated with osteopenia and osteoporosis $(\mathrm{p}<0.05)$. T-score was much lower at femoral neck site $(-3.29 \pm 0.47)$ and lumbar spine site $(-3.15 \pm 0.50)$ when compared with hip bone $(-2.40 \pm 0.68)$.

Conclusions: The present study found moderately higher prevalence of osteopenia and osteoporosis among the postmenopausal women from slum area of Ahmedabad. Results revealed that the early measurement of bone mineral density will not only help for early detection, but it will also help for the prevention of osteoporosis.
\end{abstract}

Keywords: Bone mass density, Dual-energy X-ray absorptiometry scan, Osteoporosis, Postmenopausal women

\section{INTRODUCTION}

Osteoporosis is skeletal disease characterized by decreased bone strength and increasing the risk of fractures. ${ }^{1}$ Osteoporosis is silent disorder similar to hypertension and dyslipidaemia. ${ }^{1}$ Various factors are responsible for osteoporosis such as race, family history, body weight, estrogen deficiency (menopause), low calcium intake, and others. ${ }^{2}$ Amongst these all risk factors, the estrogen deficiency is the most common factor associated with postmenopausal osteoporosis. ${ }^{2}$ This estrogen deficiency is mediated by higher level of cytokines such as interleukin 1 (IL 1), IL 6 and tumor necrosis factor $\alpha{ }^{3}$ Previously, many studies reported bone loss in Indian postmenopausal women is due to estrogen deficiency. ${ }^{4}$ In South India, approximately $30 \%$ women had post-menopause as a risk factor for developing osteoporosis. ${ }^{5}$ International osteoporosis foundation reported that 1.7 million people globally suffered from osteoporosis hip fractures. The number might increase 
to 6.3 million by 2050. In India, accurate prevalence data of postmenopausal osteoporosis are not available. However, physicians routinely seen the patients suffering from bone fractures and other complications due to the postmenopausal osteoporosis. World Bank reported that India will be second highest in the world after China in terms of postmenopausal osteoporosis cases. ${ }^{4}$ Vitamin D deficiency is very common in India at all the age groups and both sexes across the country. Vitamin D deficiency and low calcium intake are important risk factors for osteoporosis. Vitamin D deficiency causes low bone mass, muscle weakness which is increasing the risk of fracture. ${ }^{6}$ Harinarayan have studied level of $25(\mathrm{OH})-\mathrm{D}$ and bone mass density (BMD) in women of reproductive (WR) age group and postmenopausal women (PMW) in South India. ${ }^{7}$ Study reported that Vitamin D deficiency was found in $76 \%$ in WR, $70 \%$ in PMW, insufficiency in $16.5 \%$ in WR, and $23 \%$ in PMW. ${ }^{7}$

Measurement of bone mineral density is the most important test to diagnose osteoporosis. The standard test for assessing BMD is the dual-energy X-ray absorptiometry (DEXA) densitometer. It is a specialized X-ray device that accurately measures BMD at the spine, femur, and other skeletal sites. DEXA scans are convenient to patients with low exposure to radiation and 10 mins for the whole test. ${ }^{8}$ Rapid bone loss occurs in the early postmenopausal years. ${ }^{8}$ Hence, postmenopausal osteoporosis can be prevented and treated very well if diagnosed early and accurately. Hence, epidemiological surveys are useful tools to predict and evaluate the prevalence of postmenopausal osteoporosis and related risk factors in communities. Therefore, this study was aimed to evaluate the prevalence and related risk factors for postmenopausal osteoporosis by measuring bone mineral density (DEXA scan).

\section{METHODS}

\section{Patient population}

About 230 postmenopausal women of slum area of Ahmedabad (Raipur and Kalupur), Gujarat were enrolled from June-2012 to December-2013. Inclusion and exclusion criteria are mentioned in Table 1.

\section{Ethics Committee (EC) approval}

EC approval was obtained prior to start any study related analysis. All activities were performed in accordance with the ethical standards laid down in the 1964 Declaration of Helsinki and its later amendments as well as in accordance with Indian guidelines, schedule Y, good clinical practices and other applicable regulatory guidelines.

\section{Study design and study procedures}

This was a prospective, single-center, investigator-initiated study. All patients gave their written consent before enrolling into the study. Identity of the patients was kept confidential.
Table 1: Inclusion and exclusion criteria.

\begin{tabular}{|ll|}
\hline Inclusion criteria & Exclusion criteria \\
$\begin{array}{l}\text { Willing to give written } \\
\text { informed consent and to } \\
\text { follow study procedures }\end{array}$ & $\begin{array}{l}\text { History of any } \\
\text { malignancy/ } \\
\text { radiotherapy }\end{array}$ \\
\hline Between $>18$ years of age & $\begin{array}{l}\text { History of iatrogenic } \\
\text { menopause }\end{array}$ \\
\hline $\begin{array}{l}\text { Patients with } \\
\text { postmenopausal women }\end{array}$ & $\begin{array}{l}\text { History of any vertebral } \\
\text { deformities at L1-L4 } \\
\text { interfering with the } \\
\text { measurement of BMD } \\
\text { with DEXA }\end{array}$ \\
& $\begin{array}{l}\text { In the opinion of the } \\
\text { investigator, patient is } \\
\text { unable to cooperate with } \\
\text { any study procedures } \\
\text { and clinically unfit }\end{array}$ \\
\hline
\end{tabular}

DEXA: Dual energy X-ray absorptiometry, BMD: Bone mass density

Baseline parameters such as age, weight, body mass index (BMI), serum calcium, serum vitamin D, exercise, type of lifestyle, diet, smoking, family history of osteoporosis, and thyroid disorder history were recorded in standard pre-designed case record form. Eligible patients according to inclusion and exclusion criteria were underwent for DEXA scan to measure BMD at the lumbar spine, femoral neck, and hip bone. DEXA Scans were performed at Green Cross Health Checkup Center at Paldi, Ahmedabad. Laboratory investigations such as serum calcium and serum vitamin D were performed according to standard procedure at Green Cross Pathology Laboratory, Paldi, Ahmedabad. Age and BMI wise correlation with BMD was performed. Further, risk factors such as deficiency of calcium, low level of vitamin D, family history of osteoporosis, and thyroid disease history were correlated with bone mineral density. Additional necessary investigations were done as per investigator discretion.

\section{Data analysis}

Statistical analysis was performed by applying Chi-square test. Statistical analysis was performed using Graph Pad prism version 5.0. Chi-square analysis was performed to test for differences in proportions of categorical variables between two or more groups and $\mathrm{p}<0.05$ was considered as a test of significance.

\section{RESULTS}

\section{Baseline characteristics}

The demographic characteristics of study participants are summarized in Table 2. Present study included 230 postmenopausal women. Majority of the study population (47.39\%) belong to age group of 41-50 years. Further, higher percentages of study population were suffering from 
Table 2: Demographic characteristics of study participants $(n=230)$.

\begin{tabular}{|c|c|}
\hline Parameters & n $(\%)$ \\
\hline \multicolumn{2}{|l|}{ Age (years) } \\
\hline $31-40$ & $18(7.83)$ \\
\hline $41-50$ & $109(47.39)$ \\
\hline $51-60$ & $69(30)$ \\
\hline $61-70$ & $20(8.7)$ \\
\hline$>70$ & $14(6.09)$ \\
\hline \multicolumn{2}{|l|}{ BMI $\left(\mathrm{kg} / \mathrm{m}^{2}\right)$} \\
\hline Underweight $(<18.5)$ & $0(0.0)$ \\
\hline Normal (18.5-24.9) & $94(40.86)$ \\
\hline Overweight (25.0-29.9) & $75(32.60)$ \\
\hline Obese $(\geq 30)$ & $61(26.52)$ \\
\hline \multicolumn{2}{|l|}{ Vitamin D level (ng/ml) } \\
\hline Normal & $35(15.21)$ \\
\hline Deficient $(<20$ ng/ml $)$ & $195(84.78)$ \\
\hline \multicolumn{2}{|l|}{ Calcium level (mg/dL) } \\
\hline Normal (8.5-9.7 mg/dL)) & $38(16.52)$ \\
\hline Deficiency $(<8.5 \mathrm{mg} / \mathrm{dL})$ & $192(83.47)$ \\
\hline \multicolumn{2}{|c|}{ Exercise (at least 30 mins/day) } \\
\hline Yes & $173(75.21)$ \\
\hline No & $57(24.78)$ \\
\hline \multicolumn{2}{|l|}{ Diet } \\
\hline Vegetarian & $145(63.04)$ \\
\hline Non-vegetarian & $34(14.78)$ \\
\hline Mixed diet & $51(22.17)$ \\
\hline \multicolumn{2}{|c|}{ Family history of osteoporosis } \\
\hline Yes & $137(59.56)$ \\
\hline No & $93(40.43)$ \\
\hline \multicolumn{2}{|l|}{ Smoking habit } \\
\hline Yes & $12(5.12)$ \\
\hline No & $218(94.78)$ \\
\hline \multicolumn{2}{|l|}{ Thyroid disorder } \\
\hline Yes & $62(26.95)$ \\
\hline No & $168(73.04)$ \\
\hline
\end{tabular}

BMI: Body mass index

deficiency of calcium (83.47\%) and vitamin D (84.78\%). However, $40.86 \%$ women showed normal BMI. Most of the postmenopausal women $(59.56 \%)$ had family history of osteoporosis. However, only $26.95 \%$ percentage women had positive thyroid disease history.

\section{Evaluation of prevalence}

Age-specific

Age specific prevalence of osteopenia and osteoporosis at different sites (femoral and/or spine and/or hip) in postmenopausal women is shown in Table 3. Overall prevalence of osteopenia and osteoporosis among postmenopausal women were found $28.69 \%$ and $44.34 \%$, respectively. Prevalence of osteoporosis was found higher $(50.72 \%)$ in study population belongs to age between 51 and 60 years whereas the prevalence of osteopenia was higher (38.53\%) in age group (41-50). Further, $46.78 \%$ and $42.85 \%$ women had osteoporosis in 41-50 and 61-70 years age group whereas approximately similar prevalence was found in age group 51-60 years and more than 70 years in osteopenia group $(21.73 \%$ and $21.42 \%$, respectively).

\section{BMI-specific}

The correlation of BMI with osteopenia and osteoporosis in postmenopausal women is shown in Figure 1. Prevalence of osteopenia and osteoporosis was noted higher with normal BMI (43.61\% and 48.935) and then followed by overweight (37.33\% and $40 \%)$ and obese $(34.42 \%$ and $37.70 \%)$ postmenopausal women. The reverse trend was observed in postmenopausal women with normal T-score.

\section{Correlation of BMD with serum calcium level and serum vitamin D level}

The association of BMD with serum calcium and serum vitamin D among postmenopausal women was shown in Table 4. Around 59 (89.40\%) women shows serum calcium levels $<8.5 \mathrm{mg} / \mathrm{dl}$ with $-1<$ BMD $<-2.5$ whereas $91(89.21 \%)$ women had serum calcium levels $<8.5 \mathrm{mg} / \mathrm{dl}$ with $\mathrm{BMD} \geq-2.5$. Similar trend was also observed in women with serum vitamin D levels $<20 \mathrm{ng} / \mathrm{ml}$. The association of serum calcium and serum vitamin D with BMD was statistically significant $(\mathrm{p}<0.001)$.

\section{Correlation of BMD with family history of osteoporosis and history of thyroid disease}

As shown in Table 5, positive family history of osteoporosis was observed significantly higher in postmenopausal women with osteopenia and osteoporosis compared to normal postmenopausal women. In osteopenic and osteoporotic women, lower percentage of thyroid disease history was found when compared with women with absence of thyroid disease history. However, both values were found statistically significant.

\section{Mean T-score}

As shown in Figure 2, T-score was much lower at femoral neck site $(-3.29 \pm 0.47)$ and lumbar spine site $(-3.15 \pm 0.50)$ when compared with hip bone $(-2.40 \pm 0.68)$.

\section{DISCUSSION}

Osteoporosis is a bone disease distinguished by reduced bone mineral density and worsening of bone structure 
Table 3: Age specific prevalence of osteopenia and osteoporosis (femoral and/or spine and/or hip) in postmenopausal women $(\mathbf{n}=\mathbf{2 3 0})$.

\begin{tabular}{|lccccc|}
\hline Age & $\begin{array}{c}\text { Total } \\
\text { population }\end{array}$ & $\begin{array}{c}\text { Normal } \\
\text { (T-score }-\mathbf{1} \text { or higher) }\end{array}$ & $\begin{array}{c}\text { Osteopenia } \\
\text { (T-score }-\mathbf{1} \text { to-2.5) }\end{array}$ & $\begin{array}{c}\text { Osteoporosis } \\
\text { (T-score }-\mathbf{2 . 5} \text { or less) }\end{array}$ & p-value \\
\hline $31-40$ & $18(7.83)$ & $13(72.22)$ & $3(16.66)$ & $2(11.11)$ & 0.0001 \\
\hline $41-50$ & $109(47.39)$ & $16(14.68)$ & $42(38.53)$ & $51(46.78)$ & \\
\hline $51-60$ & $69(30)$ & $19(27.54)$ & $15(21.73)$ & $35(50.72)$ & \\
\hline $61-70$ & $20(8.7)$ & $9(45)$ & $3(15)$ & $8(40)$ & \\
\hline$>70$ & $14(6.09)$ & $5(35.71)$ & $3(21.42)$ & $6(42.85)$ & \\
\hline Total & $230(100)$ & $62(26.95)$ & $66(28.69)$ & $102(44.34)$ & \\
\hline
\end{tabular}

BMD: Bone mass density

Table 4: Correlation of BMD with serum calcium level and serum vitamin D level.

\begin{tabular}{|c|c|c|c|c|c|}
\hline Parameters & Yes/no & $\begin{array}{c}\text { Normal } \\
\text { (T-score }-1 \text { or higher) } \\
(n=62)\end{array}$ & $\begin{array}{c}\text { Osteopenia } \\
\text { (T-score }-1 \text { to }-2.5) \\
(n=66)\end{array}$ & $\begin{array}{c}\text { Osteoporosis } \\
\text { (T-score }-2.5 \text { or less }) \\
(\mathbf{n}=\mathbf{1 0 2})\end{array}$ & p-value \\
\hline \multirow[t]{2}{*}{$\mathrm{Ca}^{+2}$ deficiency } & Yes & $42(67.75)$ & $59(89.40)$ & $91(89.21)$ & 0.0004 \\
\hline & No & $20(32.25)$ & $7(10.60)$ & $11(10.78)$ & \\
\hline \multirow[t]{2}{*}{ Vitamin D deficiency } & Yes & $47(75.80)$ & $53(80.30)$ & $95(93.13)$ & 0.005 \\
\hline & No & $15(24.19)$ & $13(19.69)$ & $7(6.86)$ & \\
\hline
\end{tabular}

BMD: Bone mass density

Table 5: Correlation of BMD with family history of osteoporosis and history of thyroid disease.

\begin{tabular}{|c|c|c|c|c|c|}
\hline Parameters & Yes/no & $\begin{array}{c}\text { Normal } \\
\text { (T-score }-1 \text { or higher) } \\
(\mathrm{n}=62)\end{array}$ & $\begin{array}{c}\text { Osteopenia } \\
(\text { T-score }-1 \text { to }-2.5) \\
(n=66)\end{array}$ & $\begin{array}{c}\text { Osteoporosis } \\
\text { (T-score }-2.5 \text { or less }) \\
(\mathrm{n}=\mathbf{1 0 2})\end{array}$ & p-value \\
\hline \multirow[t]{2}{*}{$\begin{array}{l}\text { Family history } \\
\text { of osteoporosis }\end{array}$} & Yes & $29(46.77)$ & $39(59.09)$ & $69(67.64)$ & 0.03 \\
\hline & No & $33(53.22)$ & $27(40.9)$ & $33(32.35)$ & \\
\hline \multirow[t]{2}{*}{ Thyroid disorder } & Yes & $8(12.9)$ & $21(31.81)$ & $33(32.35)$ & 0.01 \\
\hline & No & $54(87.1)$ & $45(68.18)$ & $69(67.64)$ & \\
\hline
\end{tabular}

BMD: Bone mass density

which results into fractures. ${ }^{9}$ Osteoporosis become commonest problem of postmenopausal women globally. ${ }^{10}$ It has been reported that osteoporosis increases risk of hip fractures approximately 6 times till $2050 .{ }^{10}$ The present was conducted to predict prevalence of osteoporosis and osteopenia in postmenopausal women along with association of risk factors associated with osteoporosis and osteopenia. The results of the current study state that postmenopausal women were highly prone to femoral neck and lumbar spine fracture when compared with hip bone. Previously, none of study reported prognosis of osteoporosis with respect to different sites.

In United States of America, 55\% postmenopausal women had osteoporosis aged 50 and above. ${ }^{11}$ Previous study reported that peak incidence of osteoporosis occurs at 70-80 years of age in the Western countries. ${ }^{12}$ Garg et al. reported that $58.6 \%$ and $24.1 \%$ women had osteopenia and osteoporosis, respectively aged more than 50 years. ${ }^{13}$ In contrast, our study showed $21.73 \%$ of osteopenia and
$50.72 \%$ of osteoporosis in the age group 51-60 years. Further, $38.53 \%$ of osteopenia and $46.78 \%$ osteopenia were observed in the age group of 41-50 years. These results indicate peak incidence of postmenopausal osteoporosis is earlier when compared with western data. This can be managed by early detection and timely treatment of osteoporosis. Previously many studies reported the same results as our study. ${ }^{12,13}$

Previously, few studies reported positive correlation between BMD and BMI, stating that increases BMD with increasing BMI. ${ }^{14,15}$ However, Kataria et al., reported no correlation between BMD and BMI. ${ }^{16}$ Further, one Indian study reported negative correlation between BMD and BMI. ${ }^{17}$ Similar results were also obtained in our study, stating decreases T-score with increasing BMI. Hence, overweight may protect postmenopausal women against bone loss. This caring effect may be due to mechanical support and higher estrogen synthesis in adipose tissue. Thus, BMI has an effect on BMD and $\mathrm{BMI}$ can prevent bone loss by increasing the BMD. ${ }^{17}$ 


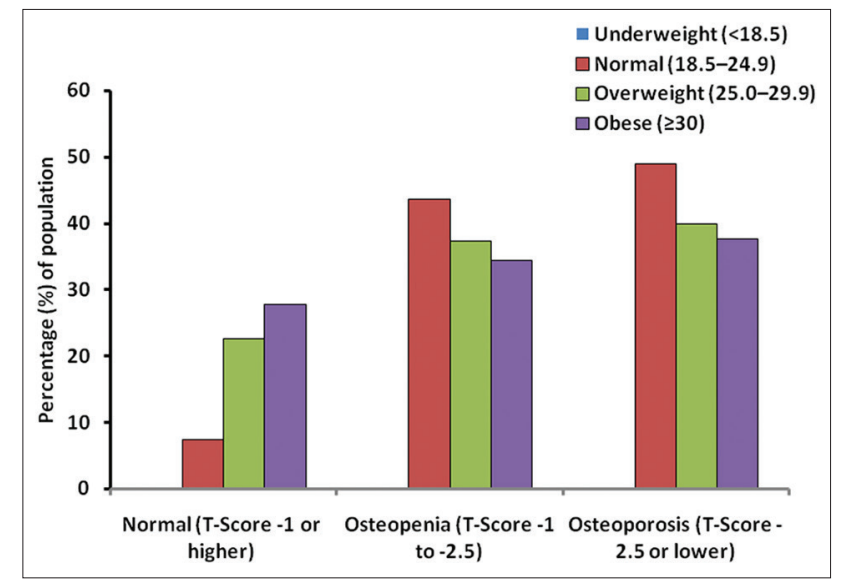

Figure 1: Correlation of T-score with body mass index $\left(\mathrm{kg} / \mathrm{m}^{2}\right)$ in postmenopausal women with osteopenia and osteoporosis. (Normal: $n=62$; osteopenia: $n=66$; osteoporosis: $n=102$ ).

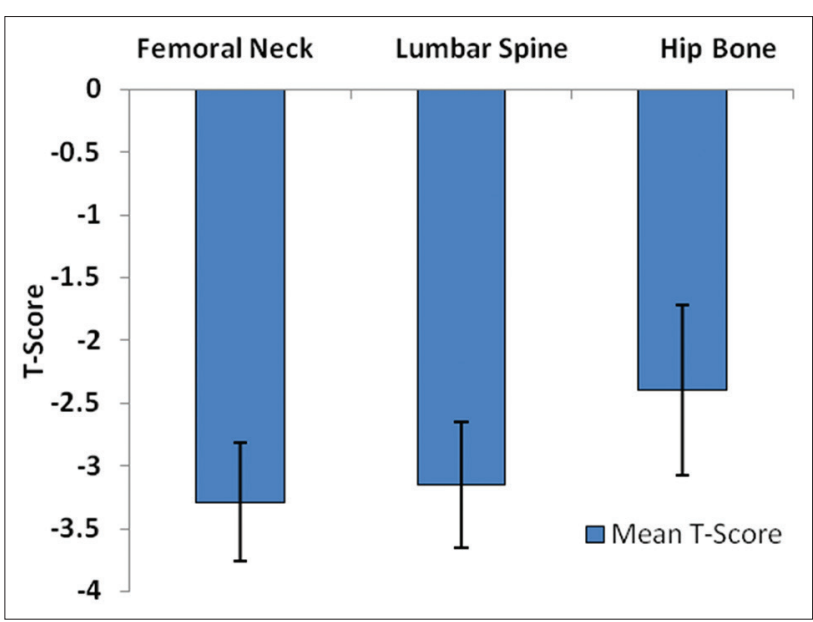

Figure 2: Mean T-score at femoral neck, lumbar spine, and hip bone.

Calcium is vital component of the bones. Loss of calcium ions is due to estrogen deficiency after menopause. This effect is mediated by indirect effects on extra skeletal calcium homeostasis as well as reduction in intestinal calcium absorption. Disturbances in the absorption of calcium ion results into hormonal imbalance and causes bone disorders such as osteopenia and osteoporosis. ${ }^{18,19}$ Previously conducted study in Western India stated that BMD decreases significantly with decreasing level of serum calcium. ${ }^{20}$ Our study results also reported the similar results for relationship between serum calcium level and BMD. Vitamin D is fundamental vitamin to maintain calcium level in bone by increasing calcium absorption in the intestines, stimulating bone resorption by increasing number of osteoclast, and maintain level of parathyroid hormone to stabilize serum calcium levels. ${ }^{21}$ Previously, many studies reported strong correlation between vitamin D deficiency and lower value of BMD. ${ }^{21-23}$ In the present study, author also obtained similar results for correlation between vitamin $\mathrm{D}$ level and BMD.
Family history is an important criterion to evaluate the risk of osteoporosis in women. Numerous is reported that risk of osteoporotic fracture was higher in women with parental or maternal family history of fracture. Family history of osteopenia, osteoporosis, and osteoporotic fracture has been recommended as a contrivance to empower people to accept preventive strategy to reduce the risk of osteoporosis in women with/without postmenopausal and premenopausal women. Previously, many studies were reported with higher prevalence of family history as an independent risk factor for osteoporosis among women with/without postmenopausal and premenopausal women. In our study, we also observed the family history as an independent risk factor associated with osteoporosis. ${ }^{24}$ In earlier published literature, few studies reported no association between subclinical hypothyroidism or subclinical hyperthyroidism and hip fracture risk or BMD in older women. ${ }^{25}$ However, one study reported positive correlation in women having subclinical hyperthyroidism and women with subclinical hypothyroidism have reduced femoral neck BMD. ${ }^{26}$ In our study, negative correlation was obtained between thyroid disease history and BMD. Additional studies are required to elucidate the mechanism for this finding.

Concluding above points, the present study predicted that higher prevalence of osteoporosis and osteopenia at an earlier age group. Positive correlation was found between osteopenia/osteoporosis and risk factors such as serum calcium deficiency, vitamin D deficiency and family history of osteoporosis. However, negative association was observed in relationship between BMI and thyroid disease history with respect to osteopenia and osteoporosis.

Funding: No funding sources

Conflict of interest: None declared

Ethical approval: The study was approved by the Institutional Ethics Committee

\section{REFERENCES}

1. Malhotra N, Mithal A. Osteoporosis in Indians. Indian J Med Res. 2008;127(3):263-8.

2. Suman VB, Perwez K, Jeganathan PS, Subbalakshmi NK, Pai SR, Shaila MD. Risk factors associated with osteoporosis - A population based study using p-Dexa technique. Int J Sci Res. 2013;3(2):1-5.

3. Menopause and Osteoporosis: ICMR. Available at http:// www.icmr.nic.in/annual/2004-05/nirrh/8\%20Chapter\%20 4\%20Menopause \%20and\%20Osteoporosis.pdf. Accessed 11 July 2015.

4. International Osteoporotic Foundation: the Asian Audit: epidemiology, costs and burden of osteoporosis in Asia, 2009. Available at http://www.iofbonehealth.org/sites/default/ files/PDFs/Audit\%20Asia/Asian_regional_audit_2009.pdf. Accessed 11 July 2015.

5. Indumati V, Patil VS, Jailkhani R. Hospital based preliminary study on osteoporosis in postmenopausal women. Indian $\mathrm{J}$ Clin Biochem. 2007;22(2):96-100.

6. Londhey V. Vitamin D deficiency: Indian scenario. J Assoc Physicians India. 2011;59:695-6. 
7. Harinarayan CV. Prevalence of vitamin D insufficiency in postmenopausal South Indian women. Osteoporos Int. 2005;16(4):397-402.

8. Aggarwal N, Raveendran A, Khandelwal N, Sen RK, Thakur JS, Dhaliwal LK, et al. Prevalence and related risk factors of osteoporosis in peri- and postmenopausal Indian women. J Midlife Health. 2011;2(2):81-5.

9. Consensus development conference: diagnosis, prophylaxis and treatment of osteoporosis. Am J Med. 1993;94:646-50.

10. Cooper C, Campion G, Melton LJ 3rd. Hip fractures in the elderly: a world-wide projection. Osteoporos Int. 1992;2(6):285-9.

11. National Osteoporosis Foundation. America's Bone Health: the State of Osteoporosis and Low Bone Mass in Our Nation. Washington, DC: National Osteoporosis Foundation; 2002.

12. Osteoporosis: what We Should Know for Self, Our Family and Patients. Available at http://www.iitk.ac.in/hc/ Osteoporosis.pdf. Accessed 09 January 2015.

13. Garg N, Kumar A, Goel P. Prevalence of osteoporosis in a rural population of Muzaffarnagar district. JIACM. 2012;13(3):185-8.

14. Sharma S, Khandelwal S. Effective risk assessment tools for osteoporosis in the Indian menopausal female. J Midlife Health. 2010;1(2):79-85.

15. Achemlal L, Bezza A, Tazi MA. Body mass index and gynecological factors as determinants of bone mass in healthy Moroccan women Science direct. Maturitas Eur Menopause J. 2007;56(4):375-82.

16. Kataria S, Pareek P, Dyadic A, Kataria K, Bhati M. The effect of body mass index on bone mineral density in pre and post menopausal women of Western Rajasthan population. Int J Biol Med Res. 2012;3(3):1899-901.

17. Jain V, Agrawal BK, Varshney A, Biswas SS. Prediction of bone mineral density by age, body mass index and menopausal status in middle socioeconomic status women of urban Kolar region of Bhopal. IOSR J Dent and Med Sci. 2013;12(3):17-21.

18. Uebelhart D, Schlemmer A, Johansen JS, Gineyts E, Christiansen C, Delmas PD. Effect of menopause and hormone replacement therapy on the urinary excretion of pyridinium cross-links. J Clin Endocrinol Metab. 1991;72:367-73.
19. Gennari C, Agnusdei D, Nardi P, Civitelli R. Estrogen preserves a normal intestinal responsiveness to 1,25-dihydroxyvitamin D3 in oophorectomized women. J Clin Endocrinol Metab. 1990;71(5):1288-93.

20. Khatake PD, Jadhav SS, Afroz S. Relation between serum calcium level, bone mineral density and blood pressure in postmenopausal women. Int J Recent Trends Sci Technol. 2013;7:86-8.

21. Balci R, Akdeniz D, Carlioglu A, Karakurt F, Derbent A, Bayram Y. Association of bone mineral density and vitamin D levels in postmenopausal women in Ankara. New J Med. 2014;31:114-7.

22. Mezquita-Raya P, Munoz-Torres M, Luna JD, Luna V, Lopez-Rodriguez F, Torres-Vela E, et al. Relation between vitamin $\mathrm{D}$ insufficiency, bone density, and bone metabolism in healthy postmenopausal women. J Bone Miner Res. 2001;16(8):1408-15.

23. Malavolta N, Pratelli L, Frigato M, Mulè R, Mascia ML, Gnudi S. The relationship of vitamin D status to bone mineral density in an Italian population of postmenopausal women. Osteoporos Int. 2005;16(12):1691-7.

24. Robitaille J, Yoon PW, Moore CA, Liu T, Irizarry-Delacruz M, Looker AC, et al. Prevalence, family history, and prevention of reported osteoporosis in U.S. women. Am J Prev Med. 2008;35(1):47-54.

25. Lee WY, Oh KW, Rhee EJ, Jung CH, Kim SW, Yun EJ, et al. Relationship between subclinical thyroid dysfunction and femoral neck bone mineral density in women. Arch Med Res. 2006;37(4):511-6.

26. Garin MC, Arnold AM, Lee JS, Robbins J, Cappola AR. Subclinical thyroid dysfunction and hip fracture and bone mineral density in older adults: the cardiovascular health study. J Clin Endocrinol Metab. 2014;99(8):2657-64.

Cite this article as: Singh A, Singh H, Patel S. Screening of bone mineral density by densitometer and correlation with serum calcium and vitamin D levels to detect early osteoporotic changes in postmenopausal women in slum areas of Raipur and Kalupur of Ahmedabad. Int J Basic Clin Pharmacol 2015;4:960-5. 